\title{
ALGUNOS PROBLEMAS “PÚBLICOS” DE LA CONTRATACIÓN ESTATAL EN COLOMBIA COMO COMPONENTES DEL ENFOQUE DE CICLO PARA LA FORMULACIÓN DE UNA POLÍTICA PÚBLICA*
}

\author{
Jorge Eduardo Vásquez Santamaría**
}

Fecha de recepción: 1 de febrero de 2017

Fecha de evaluación: 19 de septiembre de 2017

Fecha de aprobación: 21 de noviembre de 2017

Artículo de reflexión

DOI: http://dx.doi.org/10.18359/prole.3331

Forma de citación: Vásquez, J. E. (2018). Algunos problemas "públicos" de la contratación estatal en Colombia como componentes del enfoque de ciclo para la formulación de una política pública. Revista Prolegómenos Derechos y Valores, 21, 41, 79-98. DOI: http://dx.doi.org/10.18359/prole.3331

\section{RESUMEN}

A partir de la pregunta ¿qué problemas públicos, alternativas de solución y procesos consensuados de toma de decisiones desde el enfoque de ciclo hacen posible una política pública para la planeación de la contratación en la Gobernación de Antioquia? el artículo trabaja el problema público como componente inicial del enfoque de ciclo, que en este caso se emplea para exponer deficiencias en la planeación de la contratación estatal y definir cuáles de ellas son problemas públicos para una política pública. Frente a estos objetivos se aplicó un diseño metodológico basado en el modelo cualitativo, con enfoque descriptivo orientado por categorías predefinidas. Como problemas públicos se exponen y definen la indeterminación del principio de planeación, la desatención de la ley 80/1993 a la teoría económica, la incompletitud del contrato estatal, la restricción de la subasta como mecanismo únicamente aplicable para la contratación de bienes y servicios de características uniformes y de común utilización en la contratación abreviada, y la exclusión normativa de entidades estatales de la ley 80/1993.

\section{Palabras clave:}

Contratación, planeación, función administrativa, descentralización, interés general, problema público.

\footnotetext{
* Artículo resultado de la investigación "Componentes iniciales para la formulación y diseño de una política pública de planeación en procesos de contratación para la gobernación del departamento de Antioquia", adscrita a la línea de investigación "Derecho, conflicto e internacionalización", del Grupo de Investigación Orbis Iuris de la Fundación Universitaria Autónoma de las Américas (Medellín, Colombia).

** Abogado y magíster en Derecho de la Universidad de Medellín (Medellín, Colombia). Líder del Grupo de Investigación Orbis Iuris de la Fundación Universitaria Autónoma de las Américas (Medellín, Colombia).

Correo electrónico: jorge.vasquez@uam.edu.co
} 


\title{
SOME "PUBLIC" PROBLEMS OF THE STATE CONTRACTING IN COLOMBIA AS COMPONENTS OF THE APPROACH OF CYCLE TO A PUBLIC POLICY FORMULATION
}

\begin{abstract}
SUMMARY
From the following question: What public problems, solution alternatives and agreed processes of making decisions since a cycle focus, make possible a public policy to plan the Antioquia Government contracting process? This article works on the public issue as the cycle focus first component which in this case is used to set forth deficiencies in the state contracting planning process and to define which of them are actually public issues to be considered in a public policy. With regard to these goals a methodologic design based on a qualitative model was applied with a descriptive approach oriented by predefined categories. As public issues are presented and defined the planning principle indetermination, the law 80 of 1993 disregard in relation to the economic theory, the incompleteness of the state contract, the auction's restriction as only viable mechanism to obtain goods and services of uniform characteristics and common usage in the abbreviate contracting process, lastly, the normative exclusion of the state entities by the law 80 of 1993.
\end{abstract}

\section{Keywords:}

Contracting, planning, administrative function, decentralization, general interest, public issue.

\section{ALGUNS PROBLEMAS “PÚBLICOS” DA CONTRATAÇÃO ESTATAL NA COLÔMBIA COMO COMPONENTES DA ABORDAGEM DO CICLO PARA A FORMULAÇÃO DE UMA POLÍTICA PÚBLICA}

\section{RESUMO}

A partir da pergunta, ¿̇quais problemas públicos, alternativas de soluções e processos consensuais de tomada de decisões a partir da abordagem do ciclo possibilitam uma política pública para o planejamento da contratação na Governação de Antioquia? O artigo trabalha o problema público como um componente inicial da abordagem do ciclo, que neste caso é usado para expor deficiências no planejamento da contratação do Estado e para definir quais dessas são problemas públicos para uma política pública. Diante desses objetivos, foi aplicado um modelo metodológico baseado no modelo qualitativo, com abordagem descritiva orientada por categorias predefinidas. Como problemas públicos são expostos e definidos a indeterminação do princípio do planejamento, a negligência da lei 80/1993 à teoria econômica, a incompletude do contrato estadual, a restrição do leilão como mecanismo somente aplicável à contratação de bens e serviços de características uniformes e de comum utilização na contratação abreviada e a exclusão normativa de entidades estaduais da lei 80/1993.

\section{Palavras chave:}

Contratação, planejamento, função administrativa, descentralização, interesse geral, problema público. 


\section{Introducción}

Con base en la pregunta de investigación ¿qué problemas públicos, alternativas de solución y procesos consensuados de toma de decisiones desde el enfoque de ciclo hacen posible una política pública para la planeación de la contratación en la Gobernación de Antioquia? se trazó como objetivo general de investigación determinar los componentes para formular y diseñar una política pública para la planeación de la contratación estatal en la Gobernación de la mencionada entidad territorial. Entre los objetivos específicos están exponer las deficiencias propias de la Gobernación de Antioquia en la planeación de los procesos de contratación y definir cuáles de ellas se constituyen en problemas públicos, de manera que justifiquen la implementación del enfoque de ciclo para la formulación y diseño de una política pública. Para la consecución de estos propósitos se ejecutó una metodología con sustento en el modelo de investigación cualitativo con enfoque descriptivo, guiado por categorías predefinidas de investigación.

Con el problema público como la categoría desde la que inicia el análisis del enfoque de ciclo -y que al tiempo sirve para dirigir su formulación y puesta en marcha- se da preferencia al modelo cualitativo por ofrecer el potencial descriptivo, interpretativo y valorativo de un objeto social y cultural como los problemas que padece una actividad eminentemente humana como la contratación. Sobre la configuración de problemas de tipología pública presentes en la actividad contractual de entidades territoriales del Estado se hace necesario identificar y caracterizar los elementos que intervienen en las acciones dotadas de sentido de las cuales se desprenden y que impactan el entorno social, actuaciones que por la índole amplia y dinámica de la actividad contractual requirieron de un modelo flexible, disciplinado y detallado como el cualitativo, que posibilitara comprender el rol potencial de los problemas públicos para la formulación y ejecución de una política pública en la planeación de la contratación estatal.
Con el modelo cualitativo como plataforma, la investigación se delimitó en un ejercicio que parte del caso experiencial de la Gobernación del Departamento de Antioquia, sin desligarlo de la imprescindible regulación e incidencia motivada en el ámbito nacional, donde los problemas públicos de la planeación de la contratación estatal se indagaron a partir del avance descriptivo, toda vez que este se ejecuta cuando se tiene la intención de describir fenómenos, contextos, situaciones y eventos; permite especificar las propiedades, características y perfiles de las personas, grupos, procesos, objetos u otros fenómenos, dando lugar a detallar la situación prevaleciente al momento de realizar la indagación sobre el origen, naturaleza, alcance y consecuencias de los problemas de naturaleza pública que afectan la planeación de la contratación estatal.

Este escrito comparte algunas ideas de las reconstrucciones teóricas sobre las categorías predefinidas que sirvieron de base epistémica para el desarrollo del trabajo de campo. Las categorías fueron la función administrativa, la descentralización, la contratación y las políticas públicas, esta última por ser el escenario en el que se inscribe el enfoque de ciclo, y en él, el problema público, recibe mayor tratamiento. Desde aquellas reconstrucciones teóricas se emprendió la identificación y posterior descripción de las deficiencias en la planeación de los procesos de contratación, tanto desde indagaciones previas que se constituyen en precedente del escenario al cual se adscribe la Gobernación de Antioquia, como desde un trabajo de campo concentrado en su experiencia concreta. El artículo procura argumentar por qué los problemas presentados son públicos y justifican la aplicación del enfoque de ciclo para la formulación de una política pública.

\section{A. Referentes para la determinación de los problemas públicos de la planeación en la contratación estatal}

Para determinar los componentes iniciales de una política pública para la planeación en la contratación estatal de la Gobernación de Antioquia, se acogieron como categorías predefinidas la 
función administrativa, la descentralización, la contratación con el Estado, y por supuesto, las políticas públicas, ejes que se correlacionan y desde los cuales se consolida un escenario posible para la formulación y ejecución de una política centrada en problemas públicos que afecten la planeación en los procesos de contratación estatal.

Dentro de la estructura del Estado social y democrático de derecho adoptado en Colombia con la Constitución Política de 1991 y cuya concepción ideológica se inspira en principios como la libertad, la igualdad, la división del poder -materializada en el principio de la tridivisión entre los poderes públicos clásicos y la colaboración armónica entre los mismos para evitar el ejercicio absoluto y desmesurado- y el sometimiento de los particulares y las entidades públicas al Estado de derecho; la idea del papel del Estado ha sufrido inmensas transformaciones organizativas y funcionales, más aún si se enfoca el análisis en el ejercicio del poder ejecutivo.

Alberto Montaña Plata (2011) expresa que: "la administración pública es la parte del Estado que de manera más decidida debe dar desarrollo a esta nueva forma de concebirlo pues es, por excelencia, la parte de este que interactúa con la comunidad" (pp. 80-81). Pero a la importancia que tiene la administración como el poder público estatal que mantiene la interacción con los administrados, hoy deben sumarse fenómenos como el incremento en el gasto público, las tendencias a la democratización participativa y deliberativa, el crecimiento de la estructura estatal y los esfuerzos frente a la forma del funcionamiento administrativo del Estado a partir de la redistribución del poder.

Dichas tendencias encuentran lugar en la Constitución de 1991, especialmente al Estado administrador el artículo 209 lo somete al ejercicio de la función administrativa de la siguiente manera: "la función administrativa está al servicio de los intereses generales y se desarrolla con fundamento en los principios de igualdad, moralidad, eficacia, economía, celeridad, imparcialidad y publicidad, mediante la descentralización, la delegación y la desconcentración de funciones", por lo que es la función administrativa el mandato constitucional que se asigna al Estado como pilar principal de su actuar, señalando que dicha actividad la ejecuta por regla general la administración pública, situada en la gestión de lo público y dirigida al cumplimento de los fines del Estado (Montaña, 2011), pero como se mencionará, también puede\} ejercerla el poder jurisdiccional y el legislativo.

\section{La función administrativa}

La función administrativa en palabras de Gamboa (2007) tiene una íntima relación con la actuación de las autoridades administrativas:

[...] profundizar en el tipo de acciones o actividades que se pueden desarrollar bajo el concepto de administración pública implica de manera irremediable, aproximarse a todas aquellas materias con incidencia directa en la sociedad, a partir de actuaciones de las autoridades o los particulares con investidura pública, desarrolladas a través de los mecanismos o medios de acción institucional como los actos administrativos (individuales o generales) y el contrato estatal (Gamboa, 2007, p. 38).

Actividades como: la policía administrativa con las correspondientes prerrogativas de poder de coacción; la reglamentaria y normativa, la de intervención, control y vigilancia; la programadora y planificadora, la económica y la actividad de prestación de servicios públicos, están adscritas a la función administrativa, y siguiendo a Santofimio Gamboa (2007) están todas encaminadas a los presupuestos y principios de la forma de Estado, la organización territorial y la estructura político-administrativa.

Para Marín Cortés (2010) la función administrativa se vincula a la función pública, reservándose al ejercicio de una de las actividades o funciones propias de los poderes del Estado, por lo que la función pública es el género, y dentro de ella se localiza la función administrativa. Como parte de la función pública, Marín Cortés (2010) ex- 
plica que la administrativa se ha visto sometida al debate a partir del cual se debe cumplir a satisfacción con la explicación de lo que como función implica y por qué no se confunde con las demás que integran la función pública.

Desde el criterio subjetivo u orgánico la función se identifica con el órgano estatal que la cumple, con lo cual se reservaría exclusivamente al poder ejecutivo, postura frágil, pues como se mencionó líneas arriba, en la actualidad es clara la posibilidad de que los otros poderes públicos ejerzan función administrativa. Desde el criterio material o sustancial se excluye el órgano y el procedimiento para reservarse a la materia que define la actuación, y a partir del criterio mixto, se interrelaciona el órgano que cumple la función como la tipología de la actividad realizada.

Además, Marín Cortés (2015) asocia la función administrativa con el acto de ejecutar, esto es, poner en obra algo, en específico el contenido de las normas jurídicas, por lo que la función administrativa reglamenta en forma práctica lo que establecen las normas jurídicas legislativas y excepcionalmente algunas de las disposiciones de la Constitución que le reconocen a una autoridad la facultad de efectuar dicha regulación directamente. Así, la función administrativa (Marín, 2015) es una labor que se ubica en el campo práctico, es continua y tiene por finalidad la satisfacción del interés público, por lo que incluye la toma de decisiones unilaterales vinculantes, la realización de hechos administrativos, operaciones administrativas, y para nuestro caso, la celebración de contratos, todo en cumplimiento de las competencias asignadas por el ordenamiento jurídico.

En el caso de Colombia el ejercicio de la función administrativa remite por lo corriente al comportamiento del poder ejecutivo, actor tradicional y aún primordial de la impulsión y desempeño de la gobernabilidad del Estado, y con ello, de la formulación y ejecución de políticas públicas, lo que arroja una premisa con un significativo poder, mas no totalizante: en el ejercicio de la función administrativa que reviste por lo común el poder ejecutivo del Estado se radican las competencias para formular, diseñar y ejecutar políticas públicas, razón por la cual por regla general las políticas públicas se pueden asimilar a una manifestación de la función administrativa.

Se reitera que la premisa no es para nada totalizante, porque en la experiencia colombiana las políticas públicas se han venido abriendo campo desde otros actores, como es el caso del poder judicial ${ }^{1}$, o incluso, lo que parece configurarse con algunos ejercicios del sector privado. La primera posibilidad podría apoyarse más en una visión objetiva, sustancial o material de la función administrativa, si se quiere solo vincular la formulación y ejecución de políticas públicas al ejercicio de la función administrativa, en donde el poder jurisdiccional tiene algunas dimensiones viables de ejercicio en dicha función; la segunda posibilidad podría sustentarse en la prestación de un servicio público -si se tiene en cuenta que el mismo se refiere a una actividad desarrollada por el Estado o por particulares, encauzada a la satisfacción de un interés general declarado por el legislador o el constituyente-, sometido a los principios del derecho público y prestado de manera continua, general, regular y obligatoria.

\section{La descentralización}

A lo anterior debemos agregar que en Colombia la estructura político-administrativa que por regla general ejerce la función administrativa lo hace tanto en el ámbito central como en el descentralizado, dividido en servicios, colaboración y territorial. La descentralización territorial representa la división en sede administrativa del territorio a fin de posibilitar la expansión de la función administrativa a todo el Estado, lo que a su vez abre la posibilidad constitucional y legal al despliegue de competencias, entre otras, a través de la materialización de políticas públicas concentradas en problemas públicos propios

1 Un ejemplo de ello puede apreciarse en "Las órdenes de la Corte Constitucional: su papel y límites en la formulación de políticas públicas" de Diego Armando Yáñez Meza (2014). 
de la sede territorial descentralizada. Libardo Rodríguez señala en relación con la descentralización que "es la facultad que se le otorga a las entidades públicas diferentes al Estado para gobernarse por sí mismas, mediante la radicación de funciones en sus manos para que la ejerzan autónomamente" (2010, p. 23); y concibe la descentralización territorial como "el otorgamiento de competencias o funciones administrativas a las colectividades regionales o locales, para que las ejerzan en su propio nombre y bajo su propia responsabilidad" (Rodríguez, 2002, p. 54). De allí que en la descentralización territorial se conserve un potencial de formulación, diseño y ejecución de políticas públicas a partir de las competencias que el ordenamiento jurídico asigna a las entidades territoriales descentralizadas para el cumplimiento de la función administrativa.

En la descentralización territorial las entidades territoriales llevan a cabo el ejercicio de sus competencias facultadas con una autonomía delimitada por los mandatos constitucionales y legales. Con ella las entidades territoriales ejercen derechos trascendentales como lo reconoce la Corte Constitucional en las sentencias C-889/2012 y C-123/2014:

Este grado de autonomía se expresa, entre otras facetas, en los derechos de las entidades territoriales a (i) gobernarse por autoridades propias; (ii) ejercer las competencias que les correspondan; (iii) administrar los recursos y establecer los tributos necesarios para el cumplimiento de sus funciones; y (iv) participar en las rentas nacionales.

\section{La contratación estatal}

En el marco de la descentralización la normativa sobre la contratación estatal cobra especial relevancia. El actual Estatuto General de Contratación contenido en la ley 80/1993 orienta el cumplimiento de la función administrativa contractual de las entidades estatales en Colombia. Se expidió con posterioridad a la promulgación de la Constitución de 1991, incorporando para la contratación la fuerte incidencia de los principios generales del derecho, cambio que Amaya
(2016) considera sustancial en la medida que la ley 80/1993 "fue concebida como una ley de principios orientadores de la gestión contractual del Estado, a tono con la realidad del país ante el surgimiento del Estado social de derecho".

Además, como una contribución a la efectiva realización de las competencias por medio de la función administrativa, la Constitución de 1991 dotó a los cuerpos colegiados de las entidades territoriales departamentales y municipales de la capacidad de autorizar la celebración de contratos a los respectivos jefes de la administración seccional (artículos 300 y 313).

Con la preeminencia que cobran los principios, la Constitución Política modificó de forma exponencial la concepción política, administrativa y funcional del Estado, cuya base ya no son reglas o pautas determinadas de comportamiento, sino los postulados principialísticos y axiológicos, opuestos a la estructura soportada en las reglas normativas. En el caso de la contratación pública los principios se derivan de diferentes fuentes: (i) principios de rango constitucional, como legalidad, igualdad, debido proceso, buena fe, responsabilidad, prevalencia del derecho sustancial, interés público, imparcialidad, eficacia, moralidad, celeridad y publicidad; y (ii) principios de la función administrativa del artículo 209, los cuales a su vez contempla el artículo 3 del Código de Procedimiento Administrativo y Contencioso Administrativo, como propios de las actuaciones administrativas.

Enunciados los principios de rango constitucional y los de la función administrativa, hace falta citar los principios propios de la contratación estatal contenidos en el Estatuto General de Contratación (Consejo de Estado, Sala de lo Contencioso Administrativo, Sección Tercera, consejera ponente: Ruth Stella Correa Palacio, 3 de diciembre de 2007), artículo 23:

Las actuaciones de quienes intervengan en la contratación estatal se desarrollarán con arreglo a los principios de transparencia, economía y responsabilidad y de conformidad con los postulados que rigen la función 
administrativa. Igualmente, se aplicarán en las mismas las normas que regulan la conducta de los servidores públicos, las reglas de interpretación de la contratación, los principios generales del derecho y los particulares del derecho administrativo.

El artículo 23 sistematiza y agrupa el contenido y alcance de los demás principios de conformidad con su origen normativo, para ser observados en el desarrollo de las etapas y procesos contractuales, de manera que no se trata solo de un referente obligatorio para el cumplimiento de los fines estatales a través de la capacidad contractual asignada a las entidades descentralizadas, sino que deben constituir un referente normativo para la formulación, diseño y ejecución de políticas públicas, empezando por una que atienda el proceso de la planeación de la contratación estatal mediante la cual se cumple la función administrativa, pues como afirma Amaya (2016)

[...] en la contratación estatal deben concurrir en una serie de principios que garanticen la finalidad para la cual se ha diseñado la mencionada tipología de contratación y que la expresión de la función administrativa sea cumplida a cabalidad, tanto por la administración como por el particular que ejecutará el contrato (p. 110).

En este orden, el ejercicio de la función administrativa del poder ejecutivo y también de entidades territoriales gracias a la descentralización, produce que la capacidad de contratación esté en manos de las personas jurídicas territoriales, lo que posibilita asegurar la atención a necesidades propias de sus jurisdicciones a través de un ejercicio contractual fuertemente sustentado en principios generales del derecho.

Con el ejercicio de la capacidad contractual radicada en entidades territoriales, el ordenamiento jurídico proporciona una garantía para la debida prestación de servicios públicos y, con ello, para la satisfacción de las necesidades de los administrados y el cumplimiento de los fines del Estado en las jurisdicciones territoriales. Lo anterior acredita que la puesta en marcha de tan trascendental ejercicio pueda descansar en una política pública que se concentre en los problemas públicos que afectan la planeación de la contratación de esas entidades, procurando asegurar el adecuado ejercicio de las competencias de la función administrativa asignadas en el marco de la descentralización.

\section{Las políticas públicas}

Se acude a las políticas públicas toda vez que en ellas se encuentra un medio empleado por el Estado para dar respuesta a las demandas colectivas, en donde la sociedad ha tenido una participación activa tanto para formular las demandas como para promover las respuestas a sus necesidades (Vásquez, 2015). Cuando se habla de políticas públicas se hace alusión a las "decisiones de gobierno que incorporan la opinión, la participación, la corresponsabilidad y el dinero de los privados, en su calidad de ciudadanos electores y contribuyentes" (Laswell, 1996, p. 26, citado por Aguilar 2000). Para Vélez Rivera (2008, citado en Vásquez, 2015) las políticas públicas son estrategias que posibilitan la actuación política de la sociedad, sin circunscribirse a una mera respuesta de problemas delimitados. Son estrategia de gestión política y participativa que escenifica interacciones entre los actores de la vida pública; por lo que son una construcción social que facilita la relación de autoridades públicas y sectores de la sociedad.

Por lo anterior, las políticas públicas se constituyen en un mecanismo idóneo y pertinente a través del cual las distintas manifestaciones de la administración pública pueden no solo enfrentar y tratar de solucionar problemas públicos propios de su competencia, sino afrontar aquellos que afectan el ejercicio de las propias funciones que le impone el ordenamiento jurídico para atender no solo la interacción con los administrados sino la respuesta a sus demandas. Así sucede con la etapa de la planeación de la contratación estatal, con la que una autoridad administrativa busca asegurar la prestación de servicios públicos y satisfacer necesidades colectivas, asumiéndose 
el conocimiento de la mayoría de ellos a través de diversos medios de interacción y participación con los administrados.

Según Salazar (1995, p. 30, citado en Vásquez, 2015, p. 25) la política pública es el "conjunto de sucesivas respuestas del Estado frente a situaciones consideradas socialmente problemáticas", se refiere a una serie de decisiones propias del régimen político que abordan las problemáticas más urgentes de la sociedad; en sus palabras, son las "decisiones y acciones del régimen político frente a situaciones socialmente problemáticas y que buscan la resolución de las mismas" (Salazar, 1995, p. 30).

Desde esta perspectiva, las políticas públicas también se posicionan como alternativa de una autoridad administrativa, como en este caso se propone con la Gobernación de Antioquia, para acoger las problemáticas presentes en la planeación de su contratación, resaltando que para poderlas insertar en una política pública dichas problemáticas deben ser socialmente relevantes, lo que exige acreditar su incidencia y afectación en la satisfacción de intereses generales, o igualmente, en los ejercicios, procedimientos, estructura, organización, funcionamiento o capacidad de atención y respuesta efectiva de las autoridades competentes obligadas a garantizar la satisfacción de dichos intereses, como se estima que sucede con la administración pública a través del ejercicio de la contratación. En esa dirección un compromiso resulta ineludible para el tema propuesto: la identificación de las situaciones que dentro del ejercicio de la contratación estatal pueden ser denominadas como problemas públicos $y$, por ende, justifican la formulación, diseño y ejecución de una política pública².

2 No debe perderse de vista que el artículo 3 de la ley 80/1993 dispone: "Los servidores públicos tendrán en consideración que al celebrar contratos y con la ejecución de los mismos, las entidades buscan el cumplimiento de los fines estatales, la continua y eficiente prestación de los servicios públicos y la efectividad de los derechos e intereses de los administrados que colaboran con ellas en la consecución de dichos fines".

\section{El problema público para las políticas públicas}

Se explicará en esta sección la naturaleza y sentido del problema público dentro de una política pública, para ello, se acogió el enfoque de ciclo como un modelo tradicional y de uso común en Latinoamérica, con el que es posible no solo darle un lugar específico a los problemas públicos como componente de una política, sino además postular que los mismos tienen una tipología pública, lo que resulta necesario para la formulación de una política dirigida a la planeación de la contratación estatal.

El enfoque de ciclo, marco secuencial o enfoque de los libros de textos (Roth, 2008), es el más tradicional de los marcos de análisis de las políticas públicas. Planteado por Laswell, en el enfoque de ciclo la política pública se concibe como un objeto de naturaleza divisible o fragmentable en fases, sobre las cuales se puede hacer un estudio independiente y particularizado. Laswell (1956, citado en Hernández, 1999) asimila el enfoque de ciclo para el análisis de una política pública con las mismas etapas generales que definen su surgimiento, implementación y cierre, por lo que dividió en siete momentos el mencionado ciclo: inteligencia, promoción, prescripción, innovación, aplicación, terminación y evaluación.

Para Roth (2008, citado en Vásquez, 2016) las etapas del ciclo son la definición de un problema y la construcción de la agenda, la formulación de la política, la decisión, la implementación y la evaluación; mientras que para Howlett y Ramesh (1995) se identifican el reconocimiento del problema, la propuesta de una solución, la selección de la solución, su aplicación y apreciar o evaluar los resultados.

En el caso de Jones (1970) se distinguen cinco fases: identificación de un problema, formulación de soluciones, toma de decisión, implementación y evaluación (Cuervo, 2007). De esa manera inicialmente se da la identificación de una situación problemática y la inclusión de la misma dentro de la agenda política; para lo que es menester que 
la "situación sea percibida como problemática por los actores políticos y sociales. [...] se solicita entonces una acción pública y se busca que el problema esté inscrito en la agenda del sistema político" (Roth, 2004, p. 59).

Aguilar (2005) empieza por determinar el objetivo y ordenar las preferencias (identificación de un problema); indicar las opciones de acción que, por lo medios que emplean y las consecuencias que ocasionan, se consideran idóneas para llegar al objetivo (formulación de soluciones y acciones); comparar las opciones en términos de su eficiencia técnica y económica; elegir y poner en práctica la opción óptima eficiente; evaluar resultados, aprender y corregir.

A partir de la aproximación teórica al enfoque de ciclo es posible sintetizar los estadios generales que forman un proceso cíclico que permita no solo el análisis de una política pública, sino también establecer su existencia, evolución y efectos:

1. Identificar y definir el problema, 2. Inclusión del problema público en la agenda, momento en el cual se da el tono y orientación a la actuación de la autoridad, 3. Presentación de alternativas u opciones que integran el programa de ejecución para la consecución del objetivo y contrarrestar el problema público. 4. Decisión de selección de la alternativa pertinente y necesaria, 5. Definición del programa de Política a implementar, 6. Implementación del programa de política, 7. Evaluación de los efectos producidos y la consecución de los objetivos trazados (Vásquez, 2016, p. 99).

En el enfoque de ciclo se hace obligatorio identificar, describir y explicar el (los) problema(s) que da(n) lugar a una política pública. El problema debe acreditar la naturaleza de ser público, por lo que su categorización es un asunto cuidadoso que requiere tiempo e información contextual que permita una lectura adecuada del problema como un asunto público. La categorización no se genera únicamente desde los documentos, sino que requiere de un proceso de investigación empírica que permita definir, como mínimo, "la naturaleza, las causas, la duración, la dinámica, los afectados y las consecuencias posibles del problema" (Roth, 2004, p. 60, citado en Vásquez, 2016, p. 100), lo que justifica mencionar para el caso que sustenta esta revisión teórica, la proyección de un diseño metodológico cualitativo en el cual hay tránsito entre los hechos y las valoraciones a la luz de los referentes teóricos.

De allí que la identificación del problema pueda hacerse tomando como base las necesidades o requerimientos de los ciudadanos (demanda) o las consideraciones seleccionadas por los agentes estatales (oferta). Se pueden distinguir analíticamente dos elementos que se articulan: (i) la construcción del problema que urge de una intervención pública y (ii) su inscripción en la agenda política (Vásquez, 2016). Roth señala que para reconocer la realidad problemática que propone Lenoir (1986) debe existir:

[...] una transformación en la vida cotidiana de los individuos, originada por cambios sociales que afectan de manera diferenciada a los grupos sociales. [...] esta tensión inicialmente vivida como un problema individual, tiene que transformarse en un problema social y entonces el problema tiene que encontrar una formulación pública, lo cual se constituye en la segunda fase (Roth, 2004, pp. 58-59, citado en Vásquez, 2016, p. 100).

Roth (2004) afirma que los actores deben convencer a la autoridad pública de que además de ser un problema público es competencia del Estado enfrentarlo, una de las razones puede ser la necesidad de intervención del mismo, ya que es muy posible que la solución a la problemática no se pueda conseguir sin la injerencia de este, pues otros actores, por ejemplo, los que están en el mercado, no estarían dispuestos siempre a contribuir. Además, la situación que se representa en problemas debe darse desde el lenguaje del bien público y de la garantía de los derechos para que este sea tratado por la autoridad pública, lo que hace pertinente 
puntualizar siguiendo a Roth, que desde las distintas definiciones de política pública se derivan connaturalmente los momentos del enfoque de ciclo, por coincidir ante la presencia de la institucionalidad el problema público, los objetivos y el proceso para afrontar el problema y para evaluarlo (Cuervo, 2007).

El problema público también puede ser comprendido desde los aportes de Muller (2002, citado en Cuervo, 2007), para quien el carácter distintivo de la política pública es la construcción de las representaciones sociales de la acción pública y de las relaciones sociedadEstado, por lo que el problema público se vincula tanto con la causa o hecho generador de aquellas representaciones y expectativas sociales de la acción pública amparada por las competencias que impulsan el ejercicio de la función administrativa, como con las formas por medio de las cuales se debaten las demandas de los asociados con la autoridad estatal, esto es, la afección, amenaza, vulneración o riesgo de aquellos bienes jurídicamente relevantes sobre los que se espera protección.

En este sentido, el problema público, como componente inicial e ineludible de una política pública guiada desde el enfoque de ciclo, es una construcción subjetiva que con seguridad variará dependiendo de la visión de los actores involucrados, por lo que resulta conveniente la perspectiva que sobre ese problema tienen actores políticos y sociales estratégicos (Tamayo, 1997) con quienes se pueden emplear diversos medios participativos para develar la apreciación frente a la necesidad o interés que concentra el problema, y caracterizar sus dimensiones, afectados, gravedad, ramificaciones e intensidad. De acuerdo con Mejía Jiménez (2012) el problema es público cuando se entiende como una situación socialmente problemática que corresponde de manera importante a la competencia de la autoridad estatal. En definitiva, el problema público implica la toma de una decisión sobre la forma como se asume una realidad determinada, con lo cual se define el posterior desarrollo de la política pública, empezando por las alternativas posibles y necesarias que puedan ser escogidas como solución del problema.

\section{B. Aproximación a algunos problemas públicos en la planeación de la contratación estatal a partir de la experiencia colombiana}

Frente al propósito de exponer las deficiencias de la Gobernación del Departamento de Antioquia en la planeación de los procesos de contratación, los problemas con naturaleza pública se extrajeron de dos escenarios, uno teórico, general y contextual, y otro fáctico, específico y experiencial centrado en el caso de estudio. A partir de la indagación de ambos escenarios se propuso una hipótesis más que conclusión, en la medida que existen muchos contraargumentos a la misma: los problemas de naturaleza pública que aquejan la planeación de la contratación estatal se amparan en la imperfección de la normativa sobre la materia, más que en la exclusiva desviación anómala de la conducta contractual de los funcionarios administrativos. En otras palabras, un problema tan común como la corrupción parece estar más justificado en las debilidades e imperfecciones de la norma que en el preeminente actuar doloso de quien emprende la contratación a nombre del Estado. La anterior hipótesis y potencial conclusión se deriva de diagnósticos y estudios preliminares recientes de la experiencia colombiana en la que se adscribe la Gobernación de Antioquia.

A continuación se exponen como potenciales problemas para una política pública de planeación de la contratación estatal la realidad indeterminada del principio de planeación, la desatención de la ley 80/1993 a la teoría económica, a la cual se asocia la incompletitud del contrato estatal y su obligada renegociación; la restricción de la subasta como mecanismo únicamente aplicable para la contratación de bienes y servicios de características uniformes y de común utilización en la contratación abreviada; y la exclusión normativa de muchas entidades estatales de la ley 80/1993 y su sometimiento a disposiciones 
normativas excepcionales al Estatuto General de Contratación.

\section{El principio de planeación en la contratación estatal}

De todas las situaciones perfiladas como potenciales problemas públicos, la más recurrente radica en el contenido, alcance y poder vinculante de la planeación como principio, aspecto que sobresale en Amaya al preguntar ¿qué motiva el error en los procesos de contratación pública en Colombia? Y propone el principio de planeación al ser el "eje central y angular de todo lo relativo a las actividades que se desarrollan de los procesos contractuales del Estado" o como lo asevera luego, "faro en la delimitación de los aspectos procesales de esta expresión de la función administrativa que deben ser evaluados y tenidos en cuenta durante las diferentes etapas del proceso de contratación pública" (Amaya, 2016, p. 109).

Sobre la planeación recaen debates que van desde su aparente carencia de fuerza vinculante a raíz de su falta de reconocimiento positivado en el ordenamiento jurídico, sus contenidos axiológicos, su delimitación y articulación con otros principios de la contratación y la función administrativa, hasta debates como si su inobservancia o incumplimiento generara la nulidad del contrato estatal. Este último es el problema que estudia Sandoval Peña (2015), quien destaca cómo a partir del 2013 distintas salas que integran el Consejo de Estado se han visto involucradas en discusiones y toma de decisiones sobre el potencial de la planeación y los efectos de su inobservancia, dividiendo opiniones entre los que aseveran que genera la nulidad del contrato por violarse una norma superior que asegura el interés general y los que sostienen que las causales de nulidad absoluta están expresamente reconocidas en la ley y no podría reconocerse una adicional, además de que no configura un objeto ilícito, no obstante, se deja abierta la posibilidad de probar que sirve de causal para alegar el incumplimiento del contrato imputable a quien no realizó la debida planeación.
Esta dimensión del principio de planeación aparece en una sentencia del 24 de abril de 2013 de la subsección C de la sección tercera del Consejo de Estado, por medio de la cual se reconoció que el desconocimiento del deber de hacer planeación en la contratación estatal deviene en la nulidad por ilicitud en el objeto, postura que se reiteró en una sentencia del 13 de junio del mismo año. En la sentencia se aclara que si bien el deber de hacer planeación no está expresamente señalado en la legislación, se extrae del ordenamiento jurídico la idea de que el procedimiento contractual debe ser claro, específico y organizado, lo que remite al problema de la articulación y relación de la planeación con otros principios.

Sandoval Peña (2015) registra cómo desde las sentencias al principio de planeación se vincula la oportunidad de garantizar elementos como el costo de los bienes y servicios a contratar y el plazo de ejecución, también se le da valor al deber de selección objetiva, sin dejar de lado que dicho deber también está en los particulares:

[...] conforme al artículo 2o de la Ley 80 de 1993, el deber de planeación también debe ser garantizado por los particulares, primero, colaborando con la entidad dentro de la ejecución contractual a fin de que los yerros cometidos por esta puedan ser corregidos, pero adicionalmente, evitando participar en procesos de contratación en los que se evidencie el desconocimiento de tal deber (Sandoval, 2015, p. 8).

Efecto jurisprudencial que igualmente destaca Laura Amaya (2016):

- Que, a partir de lo dispuesto en el inciso $2^{\circ} \mathrm{del}$ artículo $3^{\circ}$ de la Ley 80 de 1993, comoquiera que los particulares contratistas del Estado son colaboradores de la administración, se desprende que ellos también tienen deberes en el cumplimiento del principio de la planeación lo cual implica para el particular, no solo poner de presente a la entidad contratante las deficiencias en el cumplimiento de 
las normas sobre planeación sino, además, abstenerse de celebrar contratos en los cuales existan fallas en su planeación.

- Que, en razón a lo anterior, no podrá el contratista pretender el reconocimiento y pago de derechos económicos surgidos con ocasión de un contrato estatal celebrado y ejecutado con violación al principio de la planeación, por cuanto ello sería una "apropiación indebida de los recursos públicos".

- Que, el contrato celebrado con desconocimiento del principio de la planeación adolece de objeto ilícito, por cuanto se celebró en contravía a lo dispuesto por normas imperativas que ordenan que los contratos estatales deben ser adecuadamente planeados para la satisfacción del interés general (lo anterior se soporta en lo previsto en el artículo 1519 y 1741 del Código Civil, así como en las causales contenidas en los numerales $2^{\circ}$ y $3^{\circ}$ del artículo 44 de la ley 80 de 1993).

Pero no toda falla al deber de planeación constituiría una causal para declarar la nulidad del contrato estatal. Sandoval Peña (2015) identifica tres razones en la jurisprudencia: (i) el contrato definitivamente no podría ejecutarse de cuenta de la ausencia de planeación; (ii) la ejecución del contrato depende de situaciones indefinidas; y (iii) no se podría cumplir con el objeto en los plazos establecidos si ello implica que la entidad debe incurrir en mayores gastos, postura con la que coincide Amaya (2016) que señala que la indefinición del objeto contractual a raíz de la indebida planeación generará la nulidad contractual, pues el objeto contractual nace y se configura en la etapa de la planeación.

De lo anterior se colige que la más clara aproximación a la naturaleza pública del problema trazado sobre el principio de planeación se encuentra en las aristas que componen el problema jurídico expuesto a través de la acción de tutela incoada contra las providencias del Consejo de Estado del año 2013. El juez de tutela señaló que omitir el deber de planeación no es una causal para declarar la nulidad, pues no es una causal autónoma prevista en la ley y tampoco configura un objeto ilícito, en la medida que al enmarcarse en la etapa precontractual no se asocia con las prestaciones del contrato, para concluir que la falta de planeación podría generar incumplimiento del contrato imputable a quien no realizó la debida planeación, y la configuración de un objeto ilícito dependerá de la ilicitud de las prestaciones contractuales vinculadas a la falta o indebida planeación.

Con el fallo de tutela se revocó la sentencia de 2013 y se ordenó que se profiriera una nueva, a lo cual la subsección $\mathrm{C}$ de la sección tercera del Consejo de Estado recalcó que la declaratoria de nulidad protege el orden público, y que la transgresión a una norma imperativa o que señala una prohibición legal afecta la validez del negocio, lo que amerita declarar la nulidad.

Las consideraciones definidas en la jurisprudencia sobre el deber de planeación necesariamente trasladan la atención a valoraciones sobre otra dimensión igualmente problemática de la planeación. Su naturaleza como principio resulta fuertemente cuestionada, y de ella, los efectos y alcances que debe generar en el ordenamiento jurídico, aspecto en el que Amaya (2016) deja ver la amplia relación entre la planeación y otros principios que la definen y acompañan en el proceso contractual, como es el caso de la transparencia y la eficiencia para su construcción, y de todos aquellos que por mandato legal concurren en la actividad contractual, de tal manera que "no se puede perder de vista que la ausencia de planeación afecta la eficacia, la eficiencia, la igualdad $e$ incluso al objeto del proceso, generando una afectación al interés público que se persigue con ocasión del contrato" (Amaya, 2016, p. 110). Sandoval Peña (2015) citando a Atienza y Ruiz Moreno (1991, pp. 103-105) recuerda que los principios son reconocidos como normas:

[...] (i) con un sentido general, (ii) redactadas en términos particularmente vagos, (iii) programáticas o directriz, (iv) contentivas de los valores superiores de un ordenamiento 
jurídico, (v) especialmente importantes aunque no sean del todo específicas, (vi) relevantes desde el punto de vista jerárquico, (vii) dirigidas a los órganos de aplicación $y$, finalmente, (viii) como regula iuris, esto es, como máximas de las ciencias jurídicas considerablemente generales.

De lo anterior que Sandoval Peña recuerde que la planeación se trata de un deber de la contratación. El autor acude a Vargas (2010) para señalar que es el primero de los eventos esenciales del proceso contractual, el cual debe ser eficiente, oportuno, coherente y coordinado. Se trata de una herramienta de gerencia pública que tiene por finalidad estructurar de la mejor manera un contrato (Suárez, 2014, citado en Sandoval, 2015), esto lo refuerza Sandoval Peña a partir de normas convencionales, legales y reglamentarias. Convencionalmente propone la obligación del Estado de garantizar la efectividad de los principios, deberes y derechos reconocidos también en el bloque de constitucionalidad, lugar en el que la contratación estatal debe cumplir los fines del Estado. Legalmente ubica el principio de planeación en los artículos 24 y 25 de la ley 80/1993, y reglamentariamente en el decreto 1082/2015.

La no tipificación del principio de planeación en las normas de la contratación estatal da cuenta de la estrecha y compleja relación que tiene con otros principios, por lo que su esencia y existencia dependen de la aplicación sistemática e integral de ellos, "la normatividad aplicable al principio de planeación se desarrolla a partir de la normatividad que sustenta y reviste de carácter jurídico de los demás principios aplicables a los procesos de contratación pública en Colombia" (Amaya, 2016, p. 112).

Sobre el sentido y alcance de la planeación Aponte Díaz (2014) manifiesta que las falencias que se presentan están relacionadas con una confusión de contratistas, contratantes y demás intervinientes sobre el alcance conceptual y práctico del plan, la planeación y la planificación, confusión en la cual también incurrió el legislador. Citando la modalidad de contrato de obra, Aponte Díaz (2014) afirma que en la contratación se ha limitado el concepto de planeación al asociarlo solo a la etapa precontractual y descuidándolo de las demás etapas, a sabiendas de que se trata de un sistema que garantiza el cumplimiento de los fines del Estado, y que conforme con diversas disposiciones, como el artículo 37 del decreto 1510/2013, debe ser concebido como un concepto dinámico que se entiende agotado una vez se verifica que la necesidad que motivó la contratación fue debidamente suplida. Por la confusión se suscitan muchos problemas de la contratación como las demoras en la ejecución de las obras, los sobrecostos y los fenómenos de corrupción, pero Aponte Díaz aclara:

[...] es viable considerar que los problemas que se han suscitado no parten del desconocimiento jurídico o de carecer de medios de acceso a la justicia, ni puede decirse que contractualmente se tenía la intención de no cumplir con la ley, motivo por el cual es evidente que tanto los administradores públicos, los contratistas, interventores y supervisores no han asumido desde sus funciones la planeación de manera práctica, dinámica e integral y han dejado el desarrollo de los contratos a una ejecución de términos negociales (2014, p. 180).

Una buena y real planeación debe incluir necesidades, objetivos y metas, la definición de estrategias y de medios para lograrlas, lo que exige asegurar su alcance y sentido en términos de una seguridad jurídica y dinámica que no defraude la satisfacción del interés general. Aponte Díaz (2014) expone que la confusión sobre el alcance de la planeación viene dada por la falta de delimitación expresa y la remisión a guías normativas correlacionales -en lo que coincide con Sandoval Peña (2015) y Amaya (2016) al encontrar la planeación referenciada en los artículos 24 y 25 de la ley 80/1993-, de donde se ha entendido su incidencia solo para la etapa precontractual, dimensión a la que no debe circunscribirse el alcance de ese principio: 
Desde el enfoque jurídico, una revisión de orden normativo, doctrinal y jurisprudencial evidencia que la planeación no es solo un asunto preliminar a la contratación de obras públicas: también es liminar, entre los estudios previos que plantean los términos de referencia del contrato en su dimensión objetiva y el modo fáctico, correspondiente al cumplimiento del mismo, paralelo al desarrollo y entrega a satisfacción de las obras contratadas. Pero, a su vez, en una dimensión posliminar de todo contrato y toda obra pública terminada, la planeación plantea considerar la garantía de la durabilidad de la obra en condiciones de funcionamiento adecuado, sostenibilidad económica e incluso para minimizar el impacto ambiental y social (Aponte, 2014, p. 181).

Aclarar el sentido y alcance de la planeación es una preocupación recurrente, a lo que Aponte Díaz (2014), citado por Avellaneda (2016), propone esclarecer la diferencia entre planear y planificar. Acudiendo a la definición del Departamento Nacional de Planeación (2006) explica que planear es

[...] prever para dirigir el camino hacia la consecución de una meta; administrar, para ir paso a paso, bajo circunstancias en las que concurren tanto elementos determinados como factores que son aleatorios; planear es tener un plan, una proyección, una ruta previamente trazada, algo de lo cual se dispone antes de empezar una obra pública.

Por otro lado, planificar se asocia a la optimización de recursos, desplegar una estrategia económica para que los medios que se tienen rindan al mayor nivel frente a una necesidad que los supera. El ordenamiento jurídico no emplea el término planificación sino planeación, a lo cual Aponte Díaz rescata la propuesta de Rico (2008):

[...] que el concepto pase de ser un principio enunciado jurídicamente y descrito someramente en el ordenamiento, para que se transforme en un instrumento más técnico y por ende eficiente, que permita aplicar al cumplimiento de la ley, un protocolo o manual técnico de lo que debe ser la planeación en materia de contratación pública. En dicho manual han de considerarse las tres etapas ya enunciadas, pero al mismo tiempo, corroborarse en la obra ejecutada, que cumple plenamente con el objeto contractual y con su justificación de orden social, en términos de desarrollo y bienestar para la comunidad, para hacer obras que impliquen la apertura de la democracia a la participación en la dinámica social y económica, sobre todo para los estratos de la sociedad que tradicionalmente han quedado excluidos del desarrollo.

\section{II, La desatención de la ley 80/1993 a la teoría económica}

Otro problema potencialmente público aparece en el estudio de Yuri Gorbaneff (2003) que identifica la desatención de la ley 80/1993 a la teoría económica de los proponentes, a lo cual vincula la incompletitud del contrato estatal y su obligada renegociación. Citando a Arias y Sandoval (2000) asegura que del año 1997 en adelante las demandas contra la nación en billones de pesos se cuadriplicaron en el monto pretendido. Dicho incremento lo conecta con la desatención a la teoría económica de parte de los proponentes del Estatuto General de Contratación, pues estima el autor que la ley 80/1993 tiene más contenido ideológico que cálculo económico. Según Gorbaneff el problema de base es la selección de la estructura organizacional óptima para la contratación, de donde se deriva la estructura de integración vertical, y por otro lado, la estructura de la subcontratación.

En la integración vertical se aprecia la cadena productiva en la que se encuentran fabricantes de insumos con compradores que fabrican productos y los consumidores. Dicha integración vertical suele ser explicada con la teoría de los costos de transacción, desde la que se define la organización, estructura y pertinencia de una empresa, la cual resulta necesaria para que se pueda descubrir a la contraparte con la que se desea hacer la transacción y por tanto, refleja los costos necesarios de búsqueda, negociación, 
decisión, seguimiento e imposición (Gorbaneff, 2003).

Dentro de los costos de transacción, Gorbaneff citando a Coase (1994), identifica el costo de la negociación del contrato, de donde se diferencian los valores ex ante-negociación, formulación de contingencias y responsabilidad de los agentesde los valores ex post-renegociación, arbitrajes e imposición de acuerdos-. De la racionalidad limitada de los contratantes, preocupados por ahorrar costos ex ante y ex post, se desprende el grado de completitud de un contrato.

Habrá completitud del contrato cuando haya simetría de información entre los contratantes, especificación de los activos, claridad y certeza en el costo de la negociación y verificabilidad de las contingencias, pero ante la ausencia o debilidad de este tipo de componentes se presenta la incompleción del contrato, y dicha incompletitud se liga a los ahorros que los agentes contratantes buscan hacer sobre los valores ex ante y ex post. Cuando se da la incompletez del contrato para las partes no hay claridad sobre su responsabilidad, lo que da lugar al oportunismo, en la medida que para el momento en que se siente la incidencia de la incompletitud los agentes ya han hecho sus respectivas inversiones, por lo que la empresa contratista puede verse sujeta a ser explotada por la empresa contratante, la cual buscará a cabalidad el cumplimiento del objeto contractual.

Dicho fenómeno acarrea que, ante la posibilidad de renegociación a raíz de la incompletitud del contrato, el contratista haga las inversiones, pero muy por debajo a lo esperado para poder asegurar utilidades, lo que en últimas defrauda la finalidad contratada, como lo explica Gorbaneff (2003, p. 98) "el futuro proyecta sombra al presente, $y$ la contratista, presintiendo la renegociación y la división de utilidades, hace una inversión menor a la esperada". Gorbaneff entonces propone que la ecuación contractual mantenga la igualdad o equivalencia entre los derechos y las obligaciones surgidos al momento de contratar, pues la posibilidad de renegociación es inminente, y en ella, el oportunismo de las partes contratantes.
Por otro lado, Gorbaneff (2003) sobre la ley 80/1993 sostiene que "está inspirada en la teoría económica clásica, con sus supuestos de la racionalidad limitada, información perfecta y gratuita y de la imposición perfecta y gratuita de lo pactado, que permite elegir las mejores propuestas ex ante" (p. 100), lo que remite a los criterios de la selección objetiva, que para el caso colombiano permiten una subcontratación sustentada en una buena etapa precontractual desde la que se asegura la selección de la mejor propuesta, aunque descuida la poscontractual, de donde surge un contrato incompleto, y consecuentemente el oportunismo del contratista. Para Gorbaneff no es viable establecer con certeza cuál es la mejor propuesta basándose solo en las condiciones iniciales que las partes someten a una licitación, pues es muy probable que se prevea la renegociación:

[...] de aquí la variable más importante no es el precio de la oferta o siquiera la capacidad técnica, sino la reputación de la empresa contratista y la perspectiva de una futura interacción con ella. Estas circunstancias son mucho más importantes, porque permiten establecer un ambiente de cooperación con la contratista, clave para el éxito de la renegociación (Gorbaneff, 2003, p. 104).

\section{Restricción de la subasta como mecanismo únicamente aplicable para la contratación de bienes y servicios de características uniformes y de común utilización en la contratación abreviada}

En concordancia con Safar (2016) la subasta podría emplearse como un mecanismo de evaluación del precio en las demás modalidades de selección, excluyendo solo el concurso de méritos, lo que a criterio de la autora contribuiría a garantizar mayor eficiencia y transparencia en la selección objetiva, toda vez que aseguraría beneficios como la adquisición de obras, bienes y servicios de parte del Estado al menor precio posible y con la más alta calidad requerida; para los proponentes habría un contexto muy claro y su propuesta no afectaría el costo de oportunidad, 
y se daría lugar a un mecanismo abierto, público, sucesivo y competitivo.

Safar (2016) defiende que la subasta es ideal en los casos donde hay un número importante de potenciales participantes, pues favorece la libre concurrencia y la pluralidad de oferentes que busca la selección objetiva, lo que indica lo atractivo de la oferta y una mayor competencia, esto se traduciría en la mayor reducción del precio y en un menor margen de diferencia entre cada una de las ofertas. Igualmente explica la autora que si se presentan pocos oferentes en el proceso de selección, la entidad contratante obtendría ganancia, lo que hace de la subasta el mecanismo más eficiente ante la falta de certeza del número y calidad de los oferentes, en tanto que permite a los proveedores revelar al Estado contratante quiénes tienen mejor valoración del contrato con la oferta presentada en el concurso.

En ese mismo sentido, Safar (2016) estima que la subasta es la forma de evaluación más expedita, toda vez que respecto al precio basta con que el Estado fije el máximo que cobra el mercado y lo cruce con el límite de presupuesto que está disponible para la contratación, lo que contribuye a la celeridad que debe guiar el ejercicio de la función administrativa, además de evitar problemas en la planeación.

\section{La exclusión normativa de la ley 80/1993 y el sometimiento a disposiciones excepcionales}

Fabián Marín Cortés (2015) destaca como potencial problema la exclusión normativa de muchas entidades estatales de la ley 80/1993 y su sometimiento a disposiciones excepcionales. Ballesteros Serpa recuerda que este fenómeno se conoce como la "huida del derecho administrativo en la contratación estatal" (2013, p. 11) que Alli Aranguren (2003) explica como un reto y Restrepo Medina (2007) como una tendencia actual mediante la cual entidades sometidas al régimen administrativo de la contratación estatal, se excluyen y refugian en disposiciones distintas.
Según Ballesteros a la luz de Puigpelat (2004), el fenómeno de la huida del derecho administrativo implica que "se libra a las administraciones encargadas de funciones típicamente administrativas de la rigidez propia de los procedimientos de contratación, gestión patrimonial, de control del gasto y de selección de personal" (2013, p. 11), lo que en criterio de Dromi (1998, p. 66) "implicaría una privatización de la actividad administrativa y un debilitamiento de las funciones propias del Estado en su calidad de gerente del bien común". Marín Cortés (2015) lo explica a partir de las especificidades que presenta la contratación estatal dentro de las similitudes con la contratación regulada desde el ámbito privado, para derivar de ello que en el orden constitucional el artículo 150 estableció una diferencia con el régimen de la contratación privada, al imponer al Congreso de la República la obligación de expedir un estatuto especial para la contratación pública, lo que reconocería y aseguraría las especialidades de la contratación con el Estado.

Del artículo 2 de la ley 80/1993 se colige que su finalidad inicial era regular todas las contrataciones públicas, al contrario de lo que establecía el decreto 222/1983 que reglamentaba la contratación de las entidades nacionales pero los departamentos y municipios expedían su propio régimen de contratación. Sin embargo, Marín Cortés destaca que dentro de la vigencia de la ley 80/1993, con el pasar de los años muchas materias empezaron a salirse de su marco regulatorio, como pasó con el sector salud (ley 100/1993) y con los servicios públicos domiciliarios (ley 142/1994), menguando la eficacia de la disposición de su artículo 2, fenómeno que Tafur Galvis (1997, p. 95, citado en Ballesteros, 2013, p. 12) relaciona con

[...] i) La adoptación de formas jurídicas propias de las regulaciones del derecho civil y del derecho comercial, como es el caso de la utilización por el Estado de formas societarias (de sociedades de economía mixta y sociedades comerciales) y ii) La aplicación del derecho privado dentro de formas institucionales del 
derecho público, es decir, en entidades públicas.

El fenómeno de exclusión de la ley 80/1993 encontró como límite la expedición de la ley 1150/2007, normativa con la que se trató de subsanar el proceso de exclusión al definir qué tipo de régimen obligaría a las entidades que quedaban por fuera del Estatuto General de Contratación. Para ello, el artículo 13 de la ley 1150/2007 dispuso:

Las entidades estatales que por disposición legal cuenten con un régimen contractual excepcional al del Estatuto General de Contratación de la Administración Pública, aplicarán en desarrollo de su actividad contractual, acorde con su régimen legal especial, los principios de la función administrativa y de la gestión fiscal de que tratan los artículos 209 y 267 de la Constitución Política, respectivamente según sea el caso y estarán sometidas al régimen de inhabilidades e incompatibilidades previsto legalmente para la contratación estatal.

En materia de contratación pública se entiende que una entidad está regida por la ley 80/1993 si la misma está contemplada por las disposiciones del artículo 2 de la ley 80/1993, y además, que no haya otra disposición que la excluya, lo que mantiene una fuente potencial de sobreproducción normativa para la contratación al posibilitarse la exclusión a través de legislación que formaliza disposiciones de contratación pública para materias o entidades específicas.

El fenómeno descrito es un problema que también reconoció el "Informe de evaluación de adquisiciones del país - CPAR" y que destaca la dispersión normativa en cuanto a contratación estatal (2002), calificando a la ley/1993 no como la regla general de la contratación sino como la excepción. Debido a que diversas normas legales han creado regímenes excepcionales y desarrollos reglamentarios de la misma ley 80/1993, adoptan definiciones sectoriales que desarticulan la vocación unificadora del Estatuto General de Contratación. Adicionalmente la normativa de la ley 80/1993 se consideró antitécnica y poco sistemática, con algunas instituciones ineficientes o ineficaces, y con un proceso de selección rígido que se traduce en altos costos para el Estado (2002, p. 2). Además:

En cuanto a la gerencia y administración de los contratos, encontró que existe una deficiente planeación de los contratos de la administración pública, que el sistema presupuestal no se encuentra armonizado con las disposiciones que gobiernan la contratación y que los procesos y procedimientos que siguen las entidades a efecto de aplicar la Ley 80 del 93 y sus normas reglamentarias resultan en veces anacrónicos y en todo caso asistemáticos.

El "Informe de evaluación de adquisiciones del país - CPAR" resaltó también que la corrupción y la falta de transparencia se vinculan a la baja calidad de las auditorías y controles, los controles se centran en el cumplimiento de los procedimientos y formalidades de la contratación, y los resultados de las investigaciones para las adjudicaciones dependen de decisiones políticas que privilegian amistades. Con base en estos problemas públicos se propuso al Conpes acoger una política pública que trabajara por la eficiencia en la utilización de los recursos públicos y por la transparencia para evitar la corrupción (2002).

\section{Conclusiones}

El ejercicio de la función administrativa es propio por regla general del poder ejecutivo del Estado; en las autoridades administrativas reposan las competencias con las cuales se hace obligatoria la ejecución de los contenidos normativos legales y excepcionalmente constitucionales. La práctica de las competencias que permite el ejercicio de la función administrativa, dentro del nuevo orden constitucional halla en la formulación, diseño y ejecución de políticas públicas un mecanismo que desde la interacción democrática de la administración pública con los administrados puede materializar el ejercicio de las competencias normativas para la solución de los problemas públicos, asegurándose desde 
cada entidad administrativa el cumplimiento de los fines del Estado.

En ese orden de ideas, las políticas públicas se proponen como una manifestación del ejercicio de la función administrativa orientada por las necesidades y demandas que en un marco democrático y participativo la administración pública tiene la obligación de gestionar a partir de su capacidad de ejecutar los contenidos normativos.

Aunado a lo anterior, la estructura político-administrativa que por lo corriente ejerce la función administrativa, lo hace tanto en el ámbito central de la administración como en el descentralizado, por lo que en las autoridades propias de la descentralización territorial existe un destacado potencial para ejercer la función administrativa a través de políticas públicas centradas en problemas públicos propios de su jurisdicción.

Entre las competencias que el ordenamiento jurídico asigna a las entidades descentralizadas territorialmente está la de celebrar contratos, mediante los cuales se dé cumplimiento a los fines estatales y a la satisfacción del interés general. Capacidad que el Estatuto General de Contratación de 1993 fortaleció con principios generales, referente normativo que impregna la formulación, diseño y ejecución de políticas públicas entre las que se debe incorporar la planeación de la contratación estatal a través de la cual se cumple la función administrativa de la entidad territorial.

La pertinencia de una política pública sobre la planeación de la contratación estatal de una entidad territorial abra una serie de posibilidades para identificar y definir problemas de tipología pública que afectan el cumplimiento de una función administrativa dirigida a la superación de problemas igualmente públicos. En ello resulta trascendental que los problemas deben ser públicos, esto es, situaciones o dimensiones de la realidad en un momento y temporalidad específicos, que, por sus condiciones de intensidad, gravedad, mutabilidad y efectos, atentan contra bienes jurídicamente relevantes que deben ser protegidos por los poderes del Estado, en especial en ejercicio de su función administrativa.

Así, la política pública propuesta examina una etapa puntual del proceso contractual procurando contribuir al buen desempeño de dicha actividad para el cumplimiento de los fines del Estado y la satisfacción del interés general. En otras palabras, se proyecta una política pública para contribuir al buen ejercicio político de una autoridad administrativa en la que se radican competencias para la realización efectiva de los derechos reconocidos en el Estado social de derecho.

Siguiendo la identificación y definición de los problemas públicos como primer elemento de una política pública guiada desde el enfoque de ciclo, el escenario contextual en el cual se desenvuelve la contratación estatal, arroja que los problemas que aquejan la planeación de la contratación están amparados más en la imperfección de la normativa sobre la materia que en la exclusiva desviación anómala de la conducta contractual de los funcionarios administrativos.

De todas las vaguedades y ambigüedades atribuidas a las disposiciones contractuales, la mayor atención la recibe justamente la planeación, figura principialística que por su falta de reconocimiento normativo expreso se traduce en un amplio número de problemas que afectan el ejercicio contractual. De ello que resulte posible proponer a la naturaleza, alcance y contenidos del principio de la debida planeación contractual como problema público para una política pública de la planeación de la contratación estatal.

Postular esta dimensión como problema público para una política se sustenta en diversas expresiones complejas del principio de planeación. Desde la práctica se pone en duda si es un principio rector de la contratación, desconociendo que la misma tiene un amplio asiento convencional, constitucional, legal y reglamentario del cual para nada se excluye el deber de planear, sin mencionar que con el hecho de poner en duda su naturaleza principal no solo se cuestiona la dimensión 
axiológica del Estado social de derecho sino el cambio a un ordenamiento jurídico soportado en principios como mandatos de optimización y no en un conjunto de reglas.

Del principio de planeación tampoco se dimensiona su alcance, sentido y contenidos, lo que se representa en la confusión entre planificar y planear; se reserva su incidencia a la etapa precontractual cuando debe prolongarse a la totalidad de momentos del proceso de contratación; es con frecuencia reducible al plan, perdiendo su orientación sistemática, dinámica y técnica para asegurar la realización del objeto contractual; concentra la atención de las condiciones de negociación en la etapa precontractual y descuida las propias de la poscontractual, degenerando en incompletitud del contrato y en la obligación de renegociación, e incluso mantiene el debate sobre si debe ser una causal para declarar la nulidad del contrato en los casos donde se vulnere o desconozca, o se reserva a ser una causal de incumplimiento del contrato frente a quien no ejecutó la debida planeación.

\section{Referencias}

Aguilar L. F. (2000), El estudio de las políticas públicas, 3a ed., México: Miguel Ángel Porrúa.

Aguilar, L. F. (2005). Estudio introductorio. En: G. Majone (autor). Evidencia, argumentación y persuasión en la formulación de políticas (Introducción). Ciudad de México: Colegio Nacional de Ciencia Política y Administración Pública / Consejo Nacional para la Cultura y las Artes.

Alli J. C. (2004). Derecho Administrativo y Globalización. Madrid: Civitas Ediciones. 2004. pp 191-195.

Amaya, C. F. (2016). El principio de planeación en la contratación estatal, un principio no tipificado. Vis Iuris, 20, 105-119.

Amaya, L. (2016). La violación al principio de la planeación en la contratación estatal. El cambio jurisprudencial y los efectos adversos que se desprenden de la nueva postura. Nova et Vetera, 2(16).

Aponte, I. (2014). Las fallas de planeación y su incidencia en el contrato estatal de obra. Revista Digital de Derecho Administrativo, 11, 177-207.

Avellaneda D.F. (2016). Celebración indebida de contratos al interior del ejército nacional, un reto para la transformación de la fuerza. Universidad Militar Nueva Granada. Disponible en: http://repository.unimilitar. edu.co/handle/10654/15932

Ballesteros, C. A. (2013). El régimen contractual de las empresas sociales del Estado. Bogotá: Universidad del Rosario.

Congreso de la República de Colombia. (1991). Constitución Política de Colombia.

Corte Constitucional de la República de Colombia. (2012). Sentencia C-889. M. P.: Luis Ernesto Vargas Silva.

Corte Constitucional de la República de Colombia. (2014). Sentencia C-123. M. P.: Alberto Rojas Ríos.

Cuervo, J. I. (2007). Las políticas públicas: entre los modelos teóricos y la práctica gubernamental (una revisión a los presupuestos teóricos de las políticas públicas en función de su aplicación a la gestión pública en Colombia). Bogotá: Universidad Externado de Colombia.

Departamento Nacional de Planeación. (2006). Misión de contratación: hacia una política para la eficiencia y la transparencia en la contratación pública. Tomo II. Bogotá: Giro Editores.

Dromi, R. (1998). Derecho Administrativo. Séptima edición. Ediciones Ciudad Argentina.

Gorbaneff, Y. (2003). Problemas teóricos en la contratación pública en Colombia. Cuadernos de Administración, 16(25), 91-107.

Gorbaneff, Y. (2003). La Ley 80 y la Teoría Económica. En: Revista Vniversitas. Vol. 
52. N. 105. Bogotá: Universidad Pontificia Javeriana. pp. 25 - 44.

Hernández, G. (1999). El análisis de las políticas públicas: una disciplina incipiente en Colombia. Revista de Estudios Sociales, 4, 80-91.

Howlett, M. \& Ramesh, M. (1995). Studying public policy: policy cycles and policy subsystems. Ontario: Oxford University Press.

Marín, F. (2015). La contratación estatal en Colombia. Charla magistral 17 de julio de 2015. Medellín: Universidad Pontificia Bolivariana.

Marín F. (2010) Los servicios semipúblicos domiciliarios. Bogotá: Editorial Temis S.A.

Mejía, J. (2012). Modelo de implementación de las políticas públicas en Colombia y su impacto en el bienestar social. Revista Analecta Política, 2(3), 141-164.

Montaña, A. (2011). Fundamentos de derecho administrativo. Bogotá: Universidad Externado de Colombia.

Restrepo M.A. (2007). Respuesta del Derecho Administrativo a las transformaciones recientes del Estado Social de Derecho. En "El Derecho Administrativo en los albores del siglo XXI". Editor académico: Universidad del Rosario, pp. 37- 55.

Rodríguez, L. (2010). Estructura del poder público en Colombia (12 ${ }^{\mathrm{a}}$ ed.). Bogotá: Temis.

Rodríguez, L. (2002). Derecho administrativo general y colombiano (13 ${ }^{a}$ ed.). Bogotá: Temis.

Roth, A. N. (2004). Políticas públicas. Formulación, implementación y evaluación. Bogotá: Ediciones Aurora.

Roth, A. N. (2008). Perspectivas teóricas para el análisis de las políticas públicas. Estudios Políticos, 33, pp. 67-91.

Safar, M. (2016). ¿Hay ventajas en el mecanismo de la subasta para la contratación pública en Colombia? Revista Digital de Derecho Administrativo, 15, pp.273-293.

Salazar, C. (1995). Las políticas públicas. Bogotá: Pontificia Universidad Javeriana.

Sandoval, V. A. (2015). Nulidad absoluta del contrato estatal por violación del deber de planeación. Revista de Derecho Público, 35, pp. 2-27.

Santofimio, J. O. (2007). Tratado de derecho administrativo. Tomo I. Bogotá: Universidad Externado de Colombia.

Tamayo Saéz, Manuel (1997). El análisis de las políticas públicas. En: La nueva administración pública. Compiladores: Rafael Bañon y Ernesto Carrillo. Madrid: Alianza Universidad, pp. 2 - 22.

Vargas, E. (2010). Las obras públicas, una visión pragmática del proceso general de contratación. Bogotá: Grupo Editorial Ibáñez.

Vásquez, J. E. (2015). El referencial sociojurídico para la política pública de planeación urbana en Medellín. Medellín: Fundación Universitaria Autónoma de las Américas.

Vásquez, J. E. (2016). Revisión teórica de las políticas públicas para determinar componentes iniciales de un modelo para la planeación de la contratación del departamento de Antioquia. Estudios de Derecho, 73(162), 77-105.

Vélez, R. (2008). Políticas públicas y organizaciones sociales en Medellín, en la perspectiva del derecho público y el sistema político municipal. Medellín: Universidad Autónoma Latinoamericana.

Yáñez, D. A. (2014). Las órdenes de la Corte Constitucional: su papel y límites en la formulación de políticas públicas. Revista Estudios de Derecho, LXXI(157), 237-268. 